\title{
A emergência do jornalismo profissional e do texto jornalístico no Brasil: ponto e contraponto nos debates intelectuais na década de 1950
}

Mário MESSAGI JR ${ }^{1}$

\begin{abstract}
Resumo:
A transição do jornalismo brasileiro na década de 1950 ocorreu em três diferentes frentes: nas redações, no ensino e na mentalidade da época. Esse processo alterou os valores, competências e fazeres profissionais. $\mathrm{O}$ texto jornalístico, como gênero específico, emerge nesse momento, trazendo consigo um profissional que não é mais um subproduto de outros dois campos: a literatura e a política. A ascensão do jornalismo profissional, nos moldes como ele se consolidou nas décadas seguintes, é o surgimento e o reconhecimento de uma competência específica, que orbita a produção de linguagem dentro de parâmetros técnicos e éticos. Essa transição não aconteceu sem tensões intelectuais, profissionais e pedagógicas. Este artigo descreve as transformações na mentalidade profissional a partir de autores referenciais da época, que defendiam o jornalismo da fase anterior e posterior à transição para o paradigma informativo, mostrando como se deu esse movimento por dentro dos debates que ele moveu, com as consequências na profissão e na pedagogia do jornalismo.
\end{abstract}

Palavras-chave: texto jornalístico; história do jornalismo; profissionalização; jornalismo na década de 1950; ensino de jornalismo.

\section{The emergence of professional journalism and journalistic language in Brazil: strugles pro and cons in intellectual debates over 1950's}

\begin{abstract}
:
The changes in Brazilian journalism in the 1950's took place on three fronts: newsrooms, journalism teaching and the professional mentality. This process has changed the values, skills and professional practices. The journalistic language, as a specific genre, emerges at this moment, bringing with it a professional who is no longer a by-product of two other fields: literature and politics. The rise of professional journalist, as it was consolidated in the following decades, is the emergence and recognition of a specific competence, which revolves around the production of language according some technical and ethical paterns. This transition did not happen without intellectual, professional and pedagogical tensions. This article describes the transformations in the professional mentality from main authors of the time, who defended journalism from the phase before and after the transition to the informational paradigm, showing how this movement took place within the debates that it frensied, and consequences in profession and pedagogy of journalism.
\end{abstract}

Keywords: journalistic text; history of journalism; professionalization; journalism in the 1950s; journalism teaching.

\section{El surgimiento del periodismo profesional y el texto periodístico en Brasil: punto y contrapunto en los debates intelectuales de la década de 1950}

Resumen:

1 Doutor em Ciências da Comunicação pela Universidade do Vale do Rio dos Sinos (Unisinos), pós-doutor pela University of Cape Town e professor de Comunicação na Universidade Federal do Paraná. E-mail: messagi@ufpr.br 
La transición del periodismo brasileño en la década de 1950 se produjo en tres frentes diferentes: en las redacciones, en la docencia y en la mentalidad de la época. Este proceso cambió valores, habilidades y prácticas profesionales. El texto periodístico, como género específico, surge en este momento, trayendo consigo un profesional que ya no es un subproducto de otros dos campos: la literatura y la política. El auge del periodismo profesional, tal y como se consolidó en las décadas siguientes, es el surgimiento y reconocimiento de una competencia específica, que orbita la producción del lenguaje dentro de parámetros técnicos y éticos. Esta transición no se produjo sin tensiones intelectuales, profesionales y pedagógicas. Este artículo describe las transformaciones en la mentalidad profesional a partir de los principales autores de la época, que defendieron el periodismo en la fase anterior y posterior a la transición al paradigma de la información, mostrando cómo este movimiento sucedió dentro de los debates que lideró, con las consecuencias para la profesión. y en la pedagogía del periodismo.

Palabras clave: texto periodístico; historia del periodismo; profesionalización; periodismo en la década de 1950; enseñanza del periodismo.

\section{Introdução}

As décadas de 1950 e 1960 são apontadas como o momento em que o jornalismo no Brasil adotou o paradigma informativo, se distanciando da polêmica e buscando se distinguir da literatura. "Durante muito tempo, jornalismo e literatura se confundiam. Até a segunda metade do século XX, o jornalismo era considerado um subproduto das belas artes" (RIBEIRO, 2003, p. 147).

Segundo Ribeiro, os jornais seguiam o modelo francês, com escrita bastante literária. "Os gêneros mais valorizados eram aqueles mais livres e opinativos, como a crônica, o artigo polêmico e o de fundo" (RIBEIRO, 2003, p. 148). As relações com a política também eram evidentes, os periódicos eram de pequena tiragem, financiados pelo Estado ou por grupos políticos, para ser a voz pública desses atores. "A imprensa era ainda essencialmente de opinião e a linguagem da maioria dos jornais era em geral agressiva e virulenta, marcada que estava pela paixão dos debates e das polêmicas" (RIBEIRO, 2003, p. 148). As competências, portanto, para ser um bom jornalista nesse momento são oriundas de outros campos: a literatura e a política. Escrever bem e ser um bom orador gabaritam os "homens de imprensa".

Na transição das décadas de 1950 e 1960, a ascensão do paradigma informativo é também a ascensão do jornalismo profissional. E a ascensão do jornalismo profissional é a ascensão de um tipo de competência voltada para a produção de gêneros textuais próprios do jornalismo. Não é por outro motivo que esse momento traz consigo o debate sobre a formação jornalística (aprendizado ou dom?) e o surgimento e estruturação dos cursos de jornalismo, bem como o surgimento dos handbooks de jornalismo, alguns com feições de manuais de redação, além de um debate intelectual intenso sobre o que é jornalismo, que se expressa em 
diversas obras desse momento. Perseguindo tais obras, vemos a trajetória das mentalidades profissionais da época, em disputa, num momento de transição.

\section{O texto como problema específico, o profissional e o campo}

O problema do texto jornalístico emerge no Brasil após os anos 1950, com a introdução das técnicas americanas de redação, planejamento e edição, a consolidação dos cursos de jornalismo e a publicação dos manuais (BELTRÃO, 1960; BOND, 1959, JOBIM, 1960; HOHENBERG, 1981). Antes disso, não existe enquanto problema específico. Antes de 1950, o jornalismo está tão confundido com a política que é, por um lado, pensado enquanto tal. Por outro lado, é tomado como fazer literário, importando mais a qualidade estética ou retórica do texto que sua finalidade informativa. A ligação com a política é tão antiga quanto o próprio jornalismo no Brasil, faz parte dos mitos que cunham a legitimidade social da atividade (TRAQUINA, 2004; KUNCZIK, 1997), dentro da teoria democrática, e perdura ainda hoje, mesmo em outro paradigma legitimador da atividade, a saber: o paradigma da informação. Já a subsunção do jornalismo à literatura é resultado de um processo que começa na segunda metade do século XIX, quando grandes literatos, como Machado de Assis, trabalham nas redações e os jornais publicam obras ficcionais e textos polêmicos de grande valor estético. É por esse caminho que a atividade pretende se elevar do terreno da retórica e da polêmica para o campo das artes. Por aí, constrói uma legitimidade estética e um norte utópico, uma meta gloriosa, que, por vezes, é vista como realizada, por outras, como um objetivo permanente (LIMA, 1958).

Três clássicos exemplos dessas abordagens que refletem o pensamento hegemônico sobre o jornalismo antes de 1950 são A imprensa e o dever da verdade, de Rui Barbosa, publicado em 1920; O problema da imprensa, de Barbosa Lima Sobrinho, publicado em 1923; e O jornalismo como gênero literário, de Alceu Amoroso Lima, o Tristão de Athayde, publicado em 1958. São três livros com distinções claras, que refletem posições específicas sobre o jornalismo e que irão, cada um a seu modo, deixar marcas na ideologia e nas práticas do jornalismo brasileiro. O último, por ser publicado em 1958, é extemporâneo, mas reflete uma discussão que se acumula no período anterior. Um quarto livro de relevância nesse momento é Curso de jornalismo, do precursor originalíssimo Vitorino Prata Castelo Branco, de 1945. É um livro sui generis, pois antecipa em pelo menos seis anos o início da conversão do modelo americano de jornalismo em padrão hegemônico. A quinta referência importante é 
o livro A missão da imprensa, de Carlos Lacerda, publicado em 1949. Pela data, os dois últimos livros são prova cabal de que as décadas de 1940 e 1950 foram de grandes contradições e disputas sobre o conceito de jornalismo e as práticas jornalísticas. O período marca a mudança de um paradigma hegemônico para outro, mas as contradições sobre o jornalismo existem antes disso e perduram para muito além dessa data.

Em A imprensa e o dever da verdade, Rui Barbosa começa defendendo o papel da imprensa na democracia como fundamental. Pensa, portanto, a imprensa como atividade política, imprescindível para o Estado Democrático.

\begin{abstract}
A imprensa é a vista da Nação. Por ela é que a Nação acompanha o que lhe passa ao perto e ao longe, enxerga o que lhe malfazem, devassa o que lhe ocultam e tramam, colhe o que lhe sonegam, ou roubam, percebe onde lhe alveja, ou nodoam, mede o que lhe cerceiam, ou destroem, vela pelo que the interessa, e se acautela do que a ameaça.

Sem vista mal se vive. Vida sem vista é vida no escuro, vida na soledade, vida no medo, morte em vida: o receio de tudo; dependência de todos; rumo à mercê do acaso; a cada passo acidentes, perigos, despenhadeiros. Tal a condição do país, onde a publicidade se avariou, e, em vez de ser os olhos, por onde se lhe exerce a visão, ou o cristal, que lha clareia, é a obscuridade, onde se perde, a ruim lente, que lhe turva, ou a droga maligna, que lha perverte, obstando-lhe a notícia da realidade, ou não lha deixando senão adulterada, invertida, enganosa (BARBOSA, R., 2009, p. 20-21).
\end{abstract}

Rui Barbosa defende, com todas as letras, a tese da imprensa como vigilante do poder. Ao longo do livro, deixa claro que enxerga na polêmica o real papel da imprensa, o instrumento através do qual irá questionar o Estado. Por isso, se aproxima firmemente da teoria do watchdog, do quarto poder (KUNCZIK, 1997), que emerge nos Estados Unidos no século XIX (EMERY, 1965). A imprensa se soma, por essa concepção, a um sistema que pressupõe quatro poderes. Por tal importância, quando não cumpre bem o papel que lhe cabe, causa dano proporcional à sua grandiosidade. A má imprensa é, portanto, nefasta. Diz Rui: "Se o fiel der em ladrão, não haverá, neste mundo, ladrão tão perigoso" (BARBOSA, R., 2009, p. 22). Ele defende a independência da imprensa e demonstra porque a corrupção dos jornais produz, no mais das vezes, regimes absolutistas. O livro é resultado de uma conferência que Rui Barbosa escreveu, mas que não teve a possibilidade de proferir, por estar doente. Seria seu último trabalho. 
A conferência que Rui não proferiu se situa como uma polêmica contra a relação do governo de Epitácio Pessoa ${ }^{2}$ com a imprensa. Ou seja, o livro desempenha, dentro do assunto específico, o papel que Rui defende para a imprensa como um todo: olhos que veem, voz que critica, com independência e em defesa do interesse público, o Estado. Tal concepção continua prevalecente na imagem que os jornalistas têm do seu fazer, seja no Brasil ou nos Estados Unidos. Diz o sociólogo radicado nos Estados Unidos Herbert J. Gans (2003, p. ix): "Journalism also embrace this ideal, and consider it their work to inform people so that journalists they can carry out their democratic responsabilities". ${ }^{3}$ Mas há uma distinção fundamental, nesse ponto. Rui parece próximo da tese do quarto poder como instrumento de exposição das mazelas, vinculado assim mais ao dever de informar que ao dever de polemizar. Mas, na sua concepção, vigiar impõe polemizar, debater, encontrar pelas vias da razão dialógica o melhor caminho para o Estado. Professa os valores que Jürgen Habermas (1984) mais tarde teorizaria, ao narrar a história dessa mesma imprensa polêmica e literária. Com o tempo o jornalismo vai se afastar da seara da polêmica. Gans incorpora esse valor: a imprensa deve vigiar, mas apenas para informar. Não lhe cabe debater, mas abrir espaço para o debate. Esse é um valor fundamental da imprensa liberal: pluralismo de opinião (KUNCZIK, 1997).

Rui vai afirmar outros valores que até hoje são relevantes para o jornalismo, como a independência. "Todo o bem que se haja dito, e se disser da imprensa, ainda será pouco, se a considerarmos livre, isenta e moralizada" (BARBOSA, R., 2009, p. 22). Com base nesta defesa da independência da imprensa, desce a minúcias, criticando subvenções concedidas pelo governo federal aos jornais, num ataque direto ao ex-presidente Epitácio Pessoa. Rui condena o gasto, a título de subvenção, de mil contos de réis por um ex-presidente, que assume o ato em carta póstuma, como publicidade para os jornais. É considerado como compra e perversão do real papel da imprensa. Rui é enfático: “Aí está senhores. Que mais eloqüente documento histórico se poderia imaginar, ou exigir do que este? Nele tendes confessada, por um ex-presidente da mais ortodoxa honestidade, a compra de jornais pelo governo, ou o derrame, pelo governo, de liberalidades pecuniárias entre os jornais" (BARBOSA, R., 2009, p. 27-28). O nome eufemístico "subvenção" é um acinte para Rui, pois se trata na verdade de peculato. Contra tal "culto assalariado da mentira", Rui defende a verdade, concluindo seu texto e dando sentido ao título do livro: “A República, entre nós, se

\footnotetext{
2 Epitácio Lindolfo da Silva Pessoa foi presidente da República de 1919 a 1922.

3“O jornalismo também abraça este ideal e o considera a sua função de informar o povo, só assim jornalistas podem desempenhar suas responsabilidades democráticas” (2003, p ix, tradução nossa).
} 
consagrou ao culto da mentira. Só nos salvaremos, opondo a essa idolatria a religião da verdade" (BARBOSA, R., 2009, p. 36). Ele condena tanto o governo que concede tais benefícios quanto os "escritores" que os aceitam (BARBOSA, R., 2009, p. 53).

Em momento algum, o texto perde o fio de ataque polêmico ao governo. Em nenhum momento, ele toca explicitamente em questões acerca do texto e dos procedimentos jornalísticos. O que aparece como peculiar ao jornalismo é sua relação com o poder, seu papel social, seu vínculo com a política e com a democracia, sua obrigação com a verdade.

A discussão sobre a verdade, em Rui, fica restrita a um desejo de verdade, a um dever, a uma obrigação, a um debate sobre moral, espaço onde a polêmica se situa, seja para definir deveres de Estado na relação com a imprensa, seja para definir os deveres da imprensa na relação com o Estado. Nem de longe o texto tange as formas de produção dessa verdade. A verdade é, em suma, resultado de uma vontade de verdade do polemista. Apesar de propor um jornalismo muito distinto do que é produzido hoje, os valores defendidos por Rui vão perdurar, mesmo após a mudança do jornalismo da seara polêmica, se não como metas e/ou deveres reais, ao menos como ideologia justificadora.

O livro de Rui é um bom exemplo de como a discussão se dava na década de 1920. Nesse momento, o jornalismo, na sua concepção idealizada, está obrigado a certos deveres, e é prática de escritores, de polemistas. Seu valor se vincula, sobretudo, à autoridade de quem escreve, muito distinto da verdade que se constrói pelo processo e pela forma. A competência linguística do jornalista, em 1920, é uma competência geral. O próprio Rui é um exemplo disso. Polemista de grande talento, demonstra suas qualidades de redator em ações diversas, que passam pela produção de livros e pela diplomacia. A discussão sobre o texto e as competências jornalísticas em si está oculta ou diluída.

Apenas três anos depois, Barbosa Lima Sobrinho, no livro O problema da imprensa, especifica a discussão e foca em temas que versam sobre o jornalismo em si mesmo, nas suas necessidades de regulação, na liberdade de imprensa e seus limites, no direito de resposta, etc. Diferente do texto de Rui Barbosa, que desenvolve um argumento só do começo ao fim, o livro de Barbosa Lima é uma coletânea de artigos. É um texto muito mais focado nas especificidades do jornalismo, que entra em minúcias claras, não apenas em valores gerais abstratos. Sobre a necessidade de responsabilizar a imprensa por seus atos, diz Lima Sobrinho (1997, p. 57-58):

Em face da imprensa exaltada, a existência de um freio legal, isto é, de um processo eficaz de responsabilidade, não evita, mas forçosamente atenua a violência. Existe sempre operação mental que leva o indivíduo a comparar o 
receio dos perigos a que se arrisca e a incitação que o arrasta à violência. Acrescentar o temor de uma responsabilidade efetiva vale por argumentar, naquela balança, a parte das causas de inibição.

Note-se que Lima Sobrinho não defende o cerceamento da liberdade, mas sua responsabilização. Argumenta, assim, a partir do interesse público, que deve estabelecer regras que regulem a imprensa numa sociedade democrática. Não defende a opressão da imprensa por um poder que pretenda controlá-la simplesmente. Nesse aspecto, estabelece argumentos que pensam o jornalismo a partir dele mesmo, das suas necessidades e do seu dever social. Lima Sobrinho escreve um livro fundamental que reflete uma discussão mais moderna para o momento que a de Rui Barbosa, que, por seu lado, reflete um jornalismo de longa tradição no Brasil, cujo primeiro grande jornal foi o Reverbero Constitucional Fluminense (1821-1822). O Reverbero está vinculado aos combates políticos e é muito importante em alguns avanços, como a abolição da escravatura. No entanto, na década de 1920, o debate não se restringe a como devem agir os homens de imprensa, notáveis que dedicam a vida a uma causa. O debate já começa a se deslocar dos indivíduos e suas ações para o jornalismo em si e seu papel. Lima Sobrinho pensa a imprensa mais do que os homens de imprensa, mas ainda não chega a pensar o texto na sua especificidade, tampouco a propor regras de como elaborá-lo.

Outro aspecto que é notável na obra de Lima Sobrinho é o caráter de ensaio geral, de descrição completa ou de abordagem dos principais aspectos do jornalismo. Tal estrutura será muito comum após a década de 1950, com a introdução das descrições gerais feitas pelo que chamo de manuais, ainda que não se restrinjam a ser um compêndio de regras.

Lima Sobrinho é um sopro, em 1923, pela discussão do jornalismo como algo específico, pelo menos do ponto de vista político e jurídico. Mas o livro de Tristão de Athayde, pseudônimo de Alceu Amoroso Lima, publicado em 1958, é um testemunho incontestável de que o jornalismo continuou, também, sendo pensado por longo tempo, sobretudo como parte da literatura. O livro é publicado sete anos depois de começar a reforma no Diário Carioca (RIBEIRO, 2006), que introduziria as técnicas americanas de redação e afastaria o jornalismo da literatura. De certa forma, ele sintetiza uma posição que já estava em declínio, o jornalismo já começava a se distinguir da literatura.

Tristão de Athayde não pensa o jornalismo como campo autônomo. Seu esforço é para provar que o jornalismo é um gênero da literatura e deve ser pensado teoricamente dentro dela. Logo, ele se situa na polêmica a favor dos que pretendem manter o jornalismo 
subsumido à literatura, mas contribui, contraditoriamente, para especificar a discussão, para a formulação teórica autônoma do campo. Tal qual Danton Jobim (1960) e Celso Kelly (1966), ele é um dos primeiros autores a abordar o texto jornalístico como problema específico.

Tristão de Athayde se situa dentro da literatura, pensa o jornalismo como parte dela. Busca resolver dois problemas: caracterizar o que são gêneros literários e, como um gênero específico, localizar o jornalismo como prática estética. Opta por um conceito flexível de gênero, que por um lado não o transforma em regra inflexível, tampouco o elimina completamente, como se não existisse gênero, mas apenas o reino da liberdade com as palavras.

O gênero é assim compreendido não como uma imposição ou um modelo, de fora para dentro, mas como uma livre disciplina, de dentro para fora, como princípios ordenadores determinados pela própria arte em sua função criadora. Não desaparece, como em Croce, nem se impõe, como em Brunetière, nem dita regras e se exclui um ao outro, como na retórica tradicional (LIMA, 1958, p. 15-16).

O conceito permite pensar os gêneros como flexíveis, suscetíveis de serem respeitados ou transgredidos, organizados a partir de dentro, pelas suas regras internas, mas, de toda forma, princípios de inteligibilidade. Ou seja, é possível escrever aceitando as regras que os próprios gêneros estabelecem por serem formas mais previsíveis e, portanto, de leitura mais fácil. Uma demanda por comunicabilidade rege os gêneros. Tristão de Athayde cita Welleck e Warren:

A moderna teoria dos gêneros é, claramente, descritiva. Não limita o número dos gêneros possíveis e não prescreve regras para os autores. Supõe que os gêneros tradicionais podem ser misturados e produzir um novo gênero (como a tragicomédia)... Em vez de acentuar a distinção entre gênero e gênero, interessa-se [...] em achar o denominador comum de cada gênero, sua participação em esquemas e finalidades literárias... O gênero representa, por assim dizer, uma soma de esquemas estéticos à mão, à disposição do escritor e já inteligíveis ao leitor. O bom escritor, em parte se conforma com o gênero já existente, em parte o nega (WELLECK; WARREN apud LIMA, 1958, p. 17).

E arremata: "É na base dessa concepção metodológica e racional dos gêneros literários que podemos considerar o jornalismo como um deles" (LIMA, 1958, p. 17). Tal conceito flexível serve para Tristão de Athayde incluir o jornalismo como um gênero, o que seria impossível com conceitos mais rígidos. A produção, muito mais difusa e variada dos jornais, seria dificilmente enquadrável em conceitos rígidos. Daí a necessidade de um conceito que opere com padrões, regularidades de acontecimentos linguísticos, mas não com regras rígidas. O primeiro movimento teórico vai especificar o jornalismo como gênero. 
O segundo movimento é a definição do que é literatura, posto que é necessário responder se jornalismo é literatura. O conceito utilizado é o que concebe que a literatura é o uso estético da palavra como função primeira. Diz ele:

Literatura [...] é toda expressão verbal com ênfase nos meios de expressão. Expressão verbal, antes de tudo, pois a palavra é a diferença específica da literatura entre as outras artes. Mas a palavra com valor de fim e não apenas com valor de meio. O que faz com que a História ou Filosofia, Matemática ou Física sejam diferentes de literatura, é que nelas, além da especificidade diferente do seu objeto a palavra tem apenas valor de meio (LIMA, 1958, p. 19).

É, sem dúvida, um conceito bastante elegante e pode ser aplicado a outras artes. A possibilidade de generalização é fator importante para a consistência do conceito. O movimento do corpo quando transformado em fim gera a dança ou a expressão corporal no teatro. A voz, quando tornada fim, produz o canto. A cor, pelo mesmo processo, inventa a pintura. As habitações, se passam a ser um fim em si mesmo, produzem a arquitetura. Se são apenas meios, não alçam jamais voo para o olimpo das artes.

No limite, o autor defende a tese da pura estética, enforma a defesa da arte pela arte, da arte que não deve a nada reportar, bastando-se por sua qualidade estética. Nesse extremo, o conceito exclui o jornalismo, cujo uso da linguagem para um fim, informar ou polemizar, é nítido. Por isso, Tristão de Athayde defende a tese de que a arte, sendo a transformação de um meio em fim, não pode esquecer dos fins que antecedem a arte. Ou seja, a dança não pode ser puro movimento, desconsiderando o que é o movimento como meio. A literatura não pode, igualmente, ser a arte da palavra em si, mas deve manter relação com o uso da palavra como meio. A literatura, em outras palavras, se relaciona com a filosofia, a história, as biografias, etc.

Com base nisso, Tristão de Athayde faz o último movimento para incluir o jornalismo na literatura: "Tudo é literatura desde que no seu meio de expressão, a palavra, haja uma acentuação, uma ênfase no próprio meio de expressão, que é seu valor de beleza" (LIMA, 1958, p. 22). A conclusão é imperativa: "Sendo assim, não há como negar ao jornalismo o seu cartão de entrada no recinto literário" (LIMA, 1958, p. 22). O jornalismo teria como condição ter alguma ênfase nas palavras como um fim em si mesmo. Sem isso, segundo Tristão de Athayde, “é publicidade ou propaganda, ou noticiário, ou anúncio”. Logo, o jornalismo só pode ser literatura. Não existe fora dessa condição, pois não existe sem colocar um acento nas palavras como fim. 
As portas estão abertas. O conceito, flexível, traz para a literatura diversos outros fazeres linguísticos, como grandes discursos, biografias e cartas. No esquema de Tristão de Athayde, o jornalismo é literatura em prosa, tal qual o romance, a novela, o conto e o drama, gêneros sobre os quais não se discute o pertencimento ao campo literário. Enquadra-se também no que ele chama de gêneros de apreciação, que estão voltados para a análise de algo, de um terceiro, de um referente. Nos gêneros de apreciação, estão a crítica (de obras), as biografias (de pessoas) e o jornalismo (de acontecimentos). Pelas portas abertas por Tristão de Athayde, entram também a conversação, a oratória e a epistolografia, gêneros de comunicação.

O esforço é derradeiro. O movimento teórico consistente de Tristão de Athayde vai logo se desfazer diante dos acontecimentos, do processo de transição da imprensa brasileira (ABREU, 1996). No mesmo momento em que ele está escrevendo para provar que o jornalismo é literatura, o jornalismo no Brasil começa um movimento resoluto de separação da literatura e da constituição de um campo específico, recheado de debates conceituais polêmicos, mas autônomo. No exato momento em que o jornalismo reforça a linguagem como meio, não como fim, Tristão de Athayde inclui o jornalismo na literatura pela razão inversa. Se até 1950 o jornalista deve achar uma boa história para contá-la de forma atraente, mesmo que sacrifique com isso a precisão, informar de maneira precisa é uma das regras fundamentais que a reforma jornalística irá defender. E o jornalismo passa a incorporar isso como valor canônico.

Mesmo reforçando a linguagem como meio, a reforma do jornalismo brasileiro, iniciada pelo Diário Carioca em 1951 e propagada pelo Jornal do Brasil a partir de $1956^{4}$, vai centrar muito firmemente sua discussão no texto para, é verdade, limpá-lo de qualquer pretensão literária. O texto jornalístico assume papel fundamental na definição do campo, pois será nele que o habitus $^{5}$ da profissão vai se consolidar. Por isso, se de Rui Barbosa sobra uma série de valores que o jornalismo ajusta e incorpora aparentemente sem contradições, como imagem idealizada ao menos, de Tristão de Athayde o que sobra é resistência à reforma. Ou seja, se as novas técnicas podem incorporar Rui, por outro lado elas se opõem e desconstroem o jornalismo literário, confinado a espaços específicos, mas distante do material linguístico mais usual nos jornais: o texto informativo.

4 Segundo Carlos Eduardo Lins da Silva (1990), em $O$ adiantado da hora, as inovações trazidas pela reforma foram introduzidas no Brasil por alguns jornalistas que viveram nos Estados Unidos a partir de 1940, como Pompeu de Souza, Danton Jobim e Samuel Wainer, e, posteriormente, por Alberto Dines, que havia passado pelo Los Angeles Times.

5 Segundo Bourdieu (1983), o conceito de habitus expressa o condicionamento adquirido pelo indivíduo na sua relação com a sociedade. É a forma como as regularidades sociais se internalizam no sujeito. 
Se Tristão de Athayde é um suspiro tardio de um jornalismo que entra em declínio, o livro de Carlos Lacerda, A missão da imprensa, de 1949, é precoce e mostra que as concepções que vão fundamentar as reformas na década de 1950 são anteriores a essa data. Lacerda defende a profissão contra as incursões de aventureiros e deixa claro que concebe o jornalismo como uma profissão específica:

O fato de não se exigir muito conhecimento para começar no jornalismo, aliado à circunstância de ser o jornal um estuário da ambição e da vaidade próprias e alheias, cria aparentes facilidades pelas quais toda gente julga que é, pensa que foi ou crê que pode vir a ser jornalista (LACERDA, 1990, p. $31)$.

A crítica deixa implícito seu contrário: que jornalismo demanda conhecimento, que o jornal não deve ser estuário de ambições e da vaidade e que nem toda gente pode ser jornalista. O quadro contra o qual se rebela Lacerda é pintado em cores vivas por Nilson Lage, testemunha da história e repórter do Diário Carioca a partir de 1955, sob os ventos da reforma.

Do ponto de vista formal, havia uma multidão de jornalistas, com carteiras funcionais de sindicatos (os verdadeiros e os fantasmas), de associações existentes e inexistentes, de veículos reais ou fictícios, de "cursos de jornalismo" que se limitavam a breves ciclos de palestras de políticos e figurões. Ser ou ter sido jornalista significava, para empresários, acadêmicos e profissionais liberais, um título acrescentado a seus currículos; para estelionatários, bicheiros, proxenetas e marginais de todo tipo, o direito, principalmente, à prisão especial [...]; para pequenos vigaristas e espertalhões, o poder de dar carteiradas em boates, bares, nos casos de intervenção eventual do policiamento ostensivo etc. (LAGE, 2002, p. 59-60).

No quadro das décadas de 1940 e 1950, a desvalorização da profissão dos jornalistas vai justificar tanto a defesa de Lacerda, quanto a reforma estilística. $\mathrm{O}$ amadorismo reinante e a súcia de malandros espalhados pelas redações produzem, como reação, a defesa do profissionalismo, que virá acompanhada da padronização do texto por regras que o subordinam ao trabalho de informar. Será esse profissionalismo que vai conceber o texto como fazer específico, trazendo junto, por outro lado, o excesso da tecnificação da escrita. No entanto, apesar de tecnificar o texto, é esse processo que inicia o pensamento sobre os gêneros jornalísticos como domínio de uma competência profissional específica e da linguagem como objeto de estudo autônomo.

Se não ainda tomada como uma técnica, Lacerda defendia a escrita do jornalismo como um ofício, um instrumento, não como uma arte. A ele, não agradava a gratuidade das 
palavras. Era, como é sabido, voraz polemista (WEINER, 1987) e nunca separou o político do jornalista. Apesar disso, defendia o texto como um trabalho.

Quando se requer do jornalista que seja construtor está-se a ordenar que ele veja, que mostre, que não silencie, que ouça e prove que ouviu, e não se deixe peitar nem domesticar, nem por dinheiro nem por temor, nem pela fonte maior de toda corrupção, que é a incapacidade de crer (LACERDA, 1990, p. 27).

Apesar de repetir Rui Barbosa, citando a influência explicitamente, Lacerda já se põe a refletir sobre o que é fazer jornalismo, não apenas sobre seus deveres e sua condição legal. $\mathrm{O}$ texto é o ofício do jornalista; a independência, sua condição; a crítica, seu dever.

De fato, Lacerda não versa sobre a questão do texto em si, mas antecipa tal discussão claramente, pois o jornalismo, sendo a arte de ver e mostrar, é produção de linguagem sob determinadas condições e por pessoas dotadas de certas competências. Portanto, já é possível conceituar o que é o jornalismo, não apenas o que ele deve fazer, como em Rui Barbosa, ou sobre suas condições sociais e jurídicas, como em Lima Sobrinho. Lacerda se sente em condições de elaborar uma definiç̧̃̃o:

Ouso formular a minha definição de jornalismo. De certo modo, ele é a arte de simplificar a complexidade dos fatos e das opiniões, tornando-os acessíveis à compreensão de um número apreciável de pessoas, fixando-os num momento da sua trajetória, o que confere certa permanência à sua transitoriedade. E assim, na imobilidade de um momento, neles encontra a marca da eternidade (LACERDA, 1990, p. 35).

A definição é poética, mas afirma a relação do jornalista com o transitório, com os acontecimentos do dia e seu dever de ser claro. Lacerda defende a cobertura do cotidiano, o comezinho fazer diário da imprensa e a relação com o leitor. O conceito constrói a especificidade da profissão de forma nítida e com grande lucidez, alicerce sobre o qual se apoiará a discussão do texto jornalístico. A especificidade de um é baseada na especificidade de outro. Ou seja, não existe jornalismo sem texto jornalístico e não existe texto jornalístico sem jornalista. Diz Lacerda (1990, p. 75): "Sustento que fazer jornal deve ser uma profissão e não uma distração. À força de não ser, propriamente, uma profissão para ninguém, o jornalismo entre nós chegou a ser o divertimento de todo mundo". Ao defender o jornalismo como profissão especifica, ele prepara o terreno onde vai vicejar a discussão sobre o texto. E, à frente do seu tempo, vai professar crenças que estarão na base das reformas editoriais da década de 1950 . 
Se Lacerda antecipa mudanças, Vitorino Prata Castelo Branco parece totalmente deslocado do momento em que produz. O livro Curso de jornalismo (1945) é, a um só tempo, uma das polêmicas mais claras a favor de um jornalismo que só começaria a se tornar hegemônico na década seguinte e um esforço de ensinar a profissão que só ganhará impulso também no próximo decênio. Diz ele:

Sobre a técnica jornalística, já dissemos, nada há em português, ou melhor apenas existe aquela que estamos publicando sob os olhares irônicos dos expoentes da imprensa nacional.

Quando nós outros tratamos do assunto, agitamos estas questões, publicamos os nossos trabalhos, os veteranos da imprensa, envelhecidos na tarimba, sorriem incrédulos e dizem: - Tudo isso é bobagem, o jornalista nasce jornalista, não é preciso escola, nem livro, nem nada...

Assim não pensam, felizmente, os profissionais progressistas que dia a dia procuram aperfeiçoar os seus próprios conhecimentos [...] No rol destes jornalismo adiantados, incluímos aquêles que, não encontrando aqui os meios para aperfeiçoarem-se, vão ao estrangeiro, beber, nas melhores fontes, os segredos modernos de escrever em jornais e de dirigir órgãos de imprensa (CASTELO BRANCO, 1945, p. 271).

Transparece no trecho o ambiente de grande contradição em que se instaura, precocemente, uma disputa entre o velho e o novo jornalismo, uma disputa entre os que acreditam que jornalismo é uma profissão que se aprende e se ensina e os que acreditam que jornalismo é um dom, inato. Ao mesmo tempo, Castelo Branco anuncia a mágoa com a perseguição e incompreensão que lhe cerca. Mas não está sozinho. Mesmo minoritário, há um esforço de profissionalização, que envolve as redações e a nascente academia de jornalismo.

Se guarda um tom polêmico, o livro também estrutura com impressionante organização todo um processo de aprendizado sobre o jornalismo. Escrito em lições com exercícios que devem ser desenvolvidos ao longo de um mês, o curso tem previsão de dez meses de duração, abrangendo discussões conceituais, como o tamanho da influência americana na imprensa brasileira, e conteúdos relativos à redação de textos, títulos, subtítulos, conceito de crítica, organização do jornal, processo de produção de periódicos, etc. O curso foi “atacado, apupado e apedrejado mas não vencido" (CASTELO BRANCO, 1945, p. 7), segundo seu autor.

O texto, como competência própria dos jornalistas, aparece como peça central. Diz Castelo Branco (1945, p. 31):

A arte de escrever, aplicada ao jornalismo, divide-se geralmente em três partes - a narração comum dos repórteres, o debate dos articulistas e a exposição fundamentada e profunda, literária ou científica, dos 
colaboradores, constituídas as três em escadaria que deve ser galgada pouco a pouco.

Em seguida, ele explica cada modalidade de texto e, ao longo do livro, fornece exercícios que permitem treinar tais competências. Muito à frente do seu tempo, Castelo Branco é polemista em defesa do jornalismo informativo e precursor dos manualistas. Seu papel só não é mais relevante pelo grau de incompreensão que o cercou e o fez, inclusive, abandonar a área de jornalismo.

\section{Transição nas redações}

O Diário Carioca, em 1951, encabeçado por Luís Paulistano, será o primeiro a inovar nas técnicas jornalísticas, tornando-se precursor da "era dos manuais". Pompeu de Souza será o autor do primeiro manual de estilo ou style book produzido no Brasil, para ser utilizado na redação do Diário Carioca ([1950]).

Se cabe ao Diário Carioca o mérito de ter introduzido as novas técnicas de produção jornalística, foi, porém, o Jornal do Brasil o propagador da nova escola de jornalismo.

Em junho de 1956, foi lançado o Suplemento Dominical do Jornal do Brasil (SDJB), criado pelo poeta Reynaldo Jardim, com colaboração de Mário Faustino, Ferreira Gullar e Oliveira Bastos. A publicação alcançou grande repercussão com a sua forma neoconcretista e seu conteúdo inovador, que misturava artes plásticas, literatura, ciência e outros assuntos (MELO, 2010, p. 12).

É evidente que não se pode fazer um corte seco no tempo, supondo, por um lado, que o jornalismo informativo e a prática de produção de reportagens começa, no Brasil, em 1950, tampouco que antes disso o texto não era pensado nem discutido. Nem uma coisa nem outra é verdadeira. A publicação do texto de Lacerda em 1949 e do texto de Tristão de Athayde em 1958 são exemplos de que a discussão começa antes e continua mesmo depois de 1951. Na verdade, a imprensa informativa inicia no Brasil em 1808, com a Gazeta do Rio de Janeiro, passa pelo Diário do Rio de Janeiro, a partir de 1821, e pelo Jornal do Comércio, a partir de 1827. Outro exemplo são algumas coberturas da Agência Meridional ${ }^{6}$ publicadas em $O$ Jornal nos anos 1930, que trazem boa parte das características que depois serão consagradas em manuais (MESSAGI, 2009).

6 A Agência Meridional foi a primeira grande agência de notícias do Brasil, criada em 1931 por Assis Chateaubriand (MEIRELES, 2016). 
Figura 1 - O Jornal, ano XVI, n. 4601, p. 4, 14 out. 1934

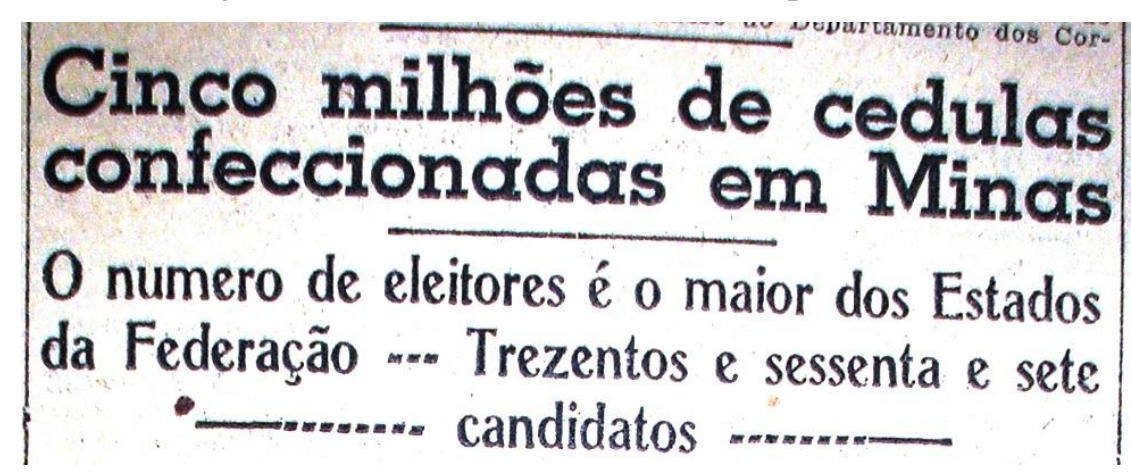

Fonte: Foto do autor, retirada no acervo do Museu Hipólito da Costa, em Porto Alegre, (RS), em 2006.

O texto diz o seguinte:

BELLO HORIZONTE, 13 (Agencia Meridional) - A campanha desenvolvida, não só na capital, como em todo Estado, foi intensa.

Enquanto as caravanas do P.P., P.R.M. e outras percorriam o interior realizando "meetings", conferencias em prol dos candidatos dos seus partidos, aqui na capital era a campanha organizada de uma maneira excepcional.

\subsection{ELEITORES}

Conforme já transmittimos, Minas possue 539.578 eleitores, occupando assim, o primeiro logar na Federação.

Calcula-se que $80 \%$ desse eleitorado compareça ás urnas, ou sejam, 431.654 suffragios, teremos um quociente eleitoral para o primeiro turno, de 11.359 votos, e admitindo-se que só 420.000 eleitores accorram ás urnas, teríamos o seguinte quociente eleitoral: - para a Constituinte mineira, 8.750, e para a Camara Federal, 11.525 votos (CINCO..., 14 out. 1934, p. 4).

É nítida a postura de informar, sobretudo, sem tomar posição, sem defender nenhum dos candidatos. Não se organiza, ainda, da forma como a técnica americana preconiza, mas é um texto de caráter claramente informativo. O jornal traz uma série de textos polêmicos, o que mostra que informação e opinião sempre estiveram presentes na história da imprensa. $\mathrm{O}$ jornalismo informativo não começa no Brasil em 1951, como também outras formas de fazer jornalismo, tomadas como superadas a partir da introdução dos manuais, vão perdurar por longa data.

Os jornais são um cadinho de formas distintas de práticas linguísticas. Mas, em alguns momentos, uma forma de fazer jornal é eleita como a mais usual, canônica, verdadeiro jornalismo em detrimento da infinidade de práticas periféricas e residuais. 
Por isso, o marco da década de 1950 é verdadeiro. A partir dali, um modelo hegemônico polêmico definha, abrindo espaço para que a informação e a comunicação passem a ser as condições de uma nova prática. A introdução das novas técnicas vai ser paulatina, o JB resolve fazer o que o Diário Carioca fez em 1951 apenas cinco anos depois, mas o ingresso desses jornais na nova lógica marca o começo de outro momento histórico. O movimento cuja reforma no JB é um marco coloca as práticas jornalísticas em discussão como nunca antes acontecera no país (FERREIRA, 1996). O texto é central nesse processo. Por isso, o momento é fundador de uma forma nova de pensá-lo.

\section{Conclusão}

O quadro é contraditório. Por um lado, as novas técnicas vão se opor ao jornalismo literário, mesmo que comparadas a ele pareçam ser um empobrecimento. Por outro, vão profissionalizar o jornal, atacando o amadorismo, o que parece um avanço. Apenas uma idealização do passado permite apagar uma das duas facetas da contradição. Ao ver o jornalismo como a produção de textos literários por grandes escritores, é de se esperar que a reforma seja combatida, vorazmente, pois empobrece o jornalismo ao retirá-lo dos braços da literatura e ao torná-lo prática de um profissional da informação, que é o profissional que corresponde à reforma. Mas mesmo por esse viés se reconhece que o movimento deu autonomia ao jornalismo, mesmo que apartado da literatura possa ser visto como menor que ela.

Já o cenário descrito por Lage (2002) faz a reforma parecer muito mais premente e justa. Na miríade de possibilidades que é e era o jornal, estavam presentes tanto a realidade dos amadores quanto a dos grandes literatos. Em relação às duas, como movimento de autonomização do jornalismo, as reformas foram relevantes. Afastar-se da literatura tem suas consequências negativas, como a diminuição do estatuto do jornalismo, deposto do olimpo da arte, mas é o que permite a constituição de um campo e, dentro dele, o estabelecimento da linguagem jornalística como problema profissional e acadêmico. Em relação ao amadorismo reinante, é um evidente avanço, ainda que a profissionalização implique fechar as portas da profissão para muitos neófitos. 
O surgimento das escolas ${ }^{7}$ também contribui para a constituição do jornalismo como objeto de estudo. Mas a existência das escolas de jornalismo sustenta-se ou, no mínimo, apoiase sobre a aceitação do jornalismo como profissão. Logo, é um movimento que relaciona diversos setores, que se ligam de forma interdependente. Daí por que, naquele momento, a academia investe em descrições do jornalismo, do jornalismo praticado pelo profissional jornalista, que é trazido para o Brasil a partir de 1951. O jornalismo profissional é o que a academia defende e sobre o que se sustenta.

A padronização textual afasta dos jornais os grandes escritores, diminui a presença dos grandes polemistas e valoriza os profissionais da técnica. Esse movimento se fazia em três frentes na década de 1950: nos jornais e entre os jornalistas, no ensino de jornalismo e nos debates intelectuais. A padronização do texto jornalístico pode ser vista, hoje, como a morte do estilo e do autor, mas foi a origem, o ponto de partida da discussão sobre o texto jornalístico como problema específico.

\section{Referências}

ABREU, Alzira Alves de (org.). A imprensa em transição. Rio de Janeiro: Fundação Getúlio Vargas, 1996.

BARBOSA. Rui. A imprensa e o dever da verdade. 4. ed. São Paulo: Edusp, 2009.

BELTRÃO, Luiz. Iniciação à filosofia do jornalismo. Rio de Janeiro: Editora Agir, 1960.

BOND, Fraser. Introdução ao jornalismo. Rio de Janeiro: Editora Agir, 1959.

BOURDIEU, Pierre. O campo científico. In: ORTIZ, Renato (org.) Bourdieu. São Paulo: Ática, 1983. Coleção Grandes Cientistas Sociais. p. 122-155.

CASTELO BRANCO, Vitorino Prata. Curso de jornalismo. São Paulo: Tipografia Cultura, 1945.

CINCO milhões de cédulas confeccionadas em Minas. O Jornal, Belo Horizonte, ano XVI, n. 4601, p. 4, 14 out. 1934.

DIÁRIO CARIOCA. Manual de redação. Disponível em: http://www.serqueira.com.br/dc/manual.htm. Acesso em: 29 dez. 2021.

7 Getúlio Vargas criou legalmente, em 13 de maio de 1943, o Curso de Jornalismo da Faculdade Nacional de Filosofia, no Rio de Janeiro. O funcionamento regular, no entanto, só começou em abril de 1948. Mas houve iniciativas anteriores, como a tentativa da Associação Brasileira de Imprensa-ABI, em 1918, de criar uma escola de jornalismo, para aprimorar a formação dos profissionais. Em 1943, na Associação dos Profissionais de Imprensa de São Paulo, acontece uma série de palestras e conferências, resultando o primeiro Curso Livre de Jornalismo no Brasil (DIAS, 2004). 
EMERY, Edwin. História da imprensa nos Estados Unidos. Rio de Janeiro: Lidador, 1965.

FERREIRA, Marieta de Moraes. A reforma do Jornal do Brasil. In: ABREU, Alzira Alves de (org.). A imprensa em transição. Rio de Janeiro: Fundação Getúlio Vargas, 1996. p. 141155.

GANS, Herbert J. Democracy and the news. Oxford: Oxford University Press, 2003.

HABERMAS, Jürgen. Do jornalismo literário aos meios de comunicação de massa. In: Mudança estrutural da esfera pública. Rio de Janeiro: Tempo Brasileiro, 1984. p. 213-229.

HOHENBERG. John. O jornalista profissional: guia às práticas e aos princípios dos meios decomunicação de massa. Rio de Janeiro: Editora Interamericana, 1981.

JOBIM, Danton. Espírito do jornalismo. Rio de Janeiro: Livraria São José, 1960.

KELLY, Celso. As novas dimensões do jornalismo. Rio de Janeiro: Livraria Agir Editora, 1966.

KUNCZIK, Michael. Conceitos de jornalismo: norte e sul. São Paulo: EDUSP, 1997.

LACERDA, Carlos. A missão da imprensa. São Paulo: EDUSP, 1990.

LAGE, Nílson. À frente, o passado. In: Federação Nacional dos Jornalistas (org.). Formação superior em jornalismo: uma exigência que interessa à sociedade. Florianópólis, SC: Imprensa da UFSC, 2002. p. 57-72.

LIMA, Alceu de Amoroso. O jornalismo como gênero literário. Rio de Janeiro: Agir, 1958.

LIMA SOBRINHO, Alexandre José Barbosa. O problema da imprensa. São Paulo: EDUSP, 1997.

LINS DA SILVA, Carlos Eduardo. O adiantado da hora. São Paulo: Summus, 1990.

MELO, Fernanda Fernandes. A reforma gráfica do caderno de esportes de "O Globo". Rio de Janeiro, 2010.

MESSAGI JÚNIOR, Mário. O texto jornalístico no centro de uma revisão da história da imprensa no Brasil. 2009. Tese (Doutorado) - Programa de Pós-Graduação em Ciências da Comunicação, Universidade do Vale do Rio dos Sinos, São Leopoldo, 2009.

RIBEIRO, Ana Paula Goulart. Jornalismo, literatura e política: a modernização da imprensa carioca nos anos 1950. Revista Estudos Históricos, v. 1, n. 31, p. 147-160, 2003. Disponível em: https://bibliotecadigital.fgv.br/ojs/index.php/reh/article/view/2186/1325. Acesso em: 21 set. 2021.

TRAQUINA, Nelson. Teorias do jornalismo. Florianópolis: Insular, 2004. 
WEINER, Samuel. Minha razão de viver. Rio de Janeiro: Record, 1987.

Submetido em: 17.07.2020.

Aprovado em: 03.12.2021. 